\title{
MILTÂNCIA FEMINISTA E ACADEMIA: SOBREVIVÊNCIA E TRABALHO VOLUNTÁRIO
}

\author{
J OANA MARIA PEDRO \\ Universidade Federal Santa Catarina
}

\begin{abstract}
Resumo: A sobrevivência de uma revista acadêmic a no Brasil depende de aportes de órgãos financiadores, de suporte institucional e de muito trabalho dos editores, nem sempre c orrespondentes a o prestígio que significa oc upar essa função. A Revista Estud os Feminista s, por ser ao mesmo tempo acadêmica e militante, tem contado com a participação de amplo trabalho voluntário de várias pessoas nela envolvidas. Este artigo discute as possibilidades de sobrevivência da Revista, as dificuldades que enfrenta por ser identificada por muitos como periódico militante e o apoio em trabalho voluntário que recebe justamente por essa identific ação.
\end{abstract}

Palavras-chave: militância; academia; trabalho voluntário.

A disputa entre militância e academia já foi alvo de muita discussão dentro do feminismo. ${ }^{1}$ Apesar das evidentes ligações entre ambas, são comuns as mútuas desqualific ações, que certamente não resistem a um olhar ma is a tento. A Revista Estudos Feministas - REF é um desses lugares em que se cruzam, se completa $m$, se misturam, linhas oriundas da militância com aquelas que provêm da academia. A academia, aqui, é pensa da como o lugar da pesquisa científica, universitária, forma dora de novas gera ções de pesquisadoras, e a militância feminista como uma atividade engajada, voluntária, tendo poralvo principal a luta pela eqüidade de gênero.

Já é consenso, na história do movimento de mulheres e feminista no Brasil, que, nos a nos oitenta, as universidades passaram a abrigar núcleos, centros, grupos de estudos, que se denominavam "estudos de mulher", "feministas" ou, ma is ta rde, "de gênero". Esses a briga va $m$, em seu interior, persona gens que havia $m$ inic ia do um movimento que ga nha va força desde 1975, quando a ONU definiu a criação do Ano Interna cional da Mulhere o iníc io da déca da da mulher. Algumas dessaspessoas tinha m sido exila das porsuas a tivida des em grupos de esquerda, a rma dos ou não, e, no exterior, tivera m conta tos com o feminismo. Alem disso, no exterior fizera m estud os que a s qua lific a va $\mathrm{m}$ pa ra ing resso em universida des.

Copyright a 2008 by Revista Estudos Feministas.

1 PEDRO, 2005. 
Evidentemente, não foi somente após o retomo do exílio que nas universida des se falou de mulher, mulheres, feminismo e gênero. $O$ trabalho pioneiro de Heleieth Saffiotti, $A$ mulher na sociedade de classes: mito e realidade, ${ }^{2}$ foi resultado de sua livre-docência, apresentada em 1967.

Foi, entreta nto, a penas em 1980, por exemplo, que foi cria do o primeiro Núcleo de Estudos Sobre a Mulher, na PUC/SP, por iniciativa de Fanny Tabak. Em 1981, surgia, na Universidade Federal do Ceará, o Núc leo de Estudos, Doc umenta ção e Informa ção so bre a Mulher - NEDIM. Ainda em 1973, Zahidé Machado ministrou o curso "Família e relações entre sexos" na Universidade Federal da Bahia. ${ }^{3}$ Pesquisas realizadas na década de 90 a pontava $\mathrm{m}$ a existência de qua se 150 núcleos $\mathrm{s}^{4}$ de estudos sedia dos em universida des. A pesquisa de Miriam Grossi ${ }^{5}$ consta tou, em 1997, a existência de 147 desses núcleos.

Os núc leoscongregava m - e congregam ainda hoje - pesquisa dorase professoras que já desenvolviam estudos de forma isolada. Costumam ser loca is de troca de experiência, intercâ mbio de doc umentação e disc ussã o teórica. Não possuem um modelo-padrã o: em cada lugar assumiram formas as ma is diversas.

Porque a universida de tomou-se o grande espaço do feminismo dosanos setenta e, mais a inda, a partir dos anos oitenta? Talvez por ser esse o lugar onde se encontrava a ma ior resistência a o govemo milita r, pa receu, para muitas, um luga r muito ma is leg itima do de a tua ção do que ospostos no Esta do recém-democratizado que lhes era oferecido. Mesmo assim, convém lembra rque essa entra da nã o foi fá cil: para muita spessoas da universidade, as mulheres que compunham esses diversos núcleos de estudos, que se formaram desde os a nos oitenta, era m considera das "a penas" feministas, porta nto sem qua lific ações acadêmicas; para as feministas que continua vam no movimento, essas mesmas mulheres eram desqualific a das como "aca dêmicas". Ainda hoje, essa tensão permanece.

Outras tensões permearam os grupos que se envolveram com o movimento de mulheres e feministas. Nos anos oitenta, um outro impasse dividiu-os: manter a militância envolvida em a tivida des como ma nifestações, a tuação direta junto às ca ma das popula res e formação de grupos de consciência ou então participar do govemo recém-saído da Dita dura. O deba te da época era, então, como mantera a utonomia, tão ca ra a o feminismo dos a nos setenta, ${ }^{6}$ como manter ativa a militância, enfim, como levar adiante todo um trabalho de transforma ção cultural da sociedade se as militantes passavam a participar de cargos dentro do govemo que as chamava? Aquilo que, para algumas, era o fim das a tividades políticas e do feminismo, era, para outras, a possibilidade de encontrar novos espaços de interferência para a mudança da sociedade e/ou para buscar altemativas individuais de carreiras.

Esse confronto entre militância e academia ultrapassou os anos oitenta. A Revista Estudos Feministas, cria da em 1992, foi tributária desse debate. ${ }^{7}$ Na primeira fa se da Revista pode serobservada, ta mbém, uma preocupação com a a utonomia em rela ção a qualquer tipo de instituição. Evidentemente, não foi consenso total essa decisão. Convém lembrar que não era somente o movimento feminista no Bra sil que esta va envolvido nesse debate. Os movimentos, em outros países da Améric a Latina, ta mbém discutiam as vantagense as desvanta gens da instituciona lização. No Encontro Feminista de San Bema rdo, na Argentina,

\footnotetext{
2 SAFFIOTI, 1979.

${ }^{3}$ Ana Alice COSTA e Cecília SARDENBERG, 1994.

${ }^{4}$ COSTA e SARDENBERG, 1994, p. 389.

5 GROSSI, 2004.

${ }^{6}$ Sonia MIGUEL, 1988.

7 PEDRO, 2006, p. 53-63.
} 
em 1990, as organizadoras do evento chegaram a rejeitar a ajuda govemamental que receberam. ${ }^{8}$

Foi em meio a esse deba te que a Revista Estudos Feminista s foi criada, em 1992, e, embora sediada inicia Imente no Centro Interdisciplinar de Estudos Contemporâneos da Escola de Comunic ação da Universidade Federal do Rio de Janeiro - UFR, o apoio da Fundação Ford era que Ihe garantia a a utonomia em relaçã o à instituição universitá ria. A intenção, de acordo com Lena Lavinas, era não ser "diretamente institucional". E mais: dentre outrasinova ções, pretendia-se "uma rotativida de da editoria da revista a cada do is ou três anos, de modo a contemplar, da forma mais democrática e ampla possível, a plura lidade das orientações acadêmicas que fazem a riqueza do campo e criam novos nexos disciplinares". ${ }^{9}$ Essa rotatividade da Revista estava ligada à sua ambição de "se a fastar de qualquer conota ção instituc ional". ${ }^{10}$ Ao mesmo tempo, porém, havia, sim, uma preocupação em darpara a Revista um suporte acadêmico. O número zero, datado de 1992, foi lança do durante a reunião a nual da Associação Nacional de Pós-Graduação e Pesquisa em Ciências Socia is (ANPOCS), a lém disso, Lena Lavinas, que assina o primeiro editorial,11 dizia que a Revista tinha como pressuposto a indissociabilidade entre "prática acadêmica e prática política", a pesar de ter "autonomia e dinâmica próprias". ${ }^{12}$ Assim, a proposta pretendia unir militância e rigoraca dêmico.

Funcionando, portanto, em regime de rodízio institucional, a segunda sede da Revista, onde permaneceu durante o ano de 1995 a té meados de 1996, foi o Programa de Pós-Graduação em Ciências Socia is da Universidade do Estado do Rio de Janeiro e o Instituto de Filosofia e Ciências Socia is da UFRJ. Entre o segundo semestre de 1996 e 1999, a Revista foi a colhida a penas pelo Instituto de Filosofia e Ciências Socia is da UFRJ.

Em relação a recursos, a partir de 1994 a Revista passou a contar com o apoio do programa FINEP, do CNPq e da Fundação Universitária J osé Bonifá cio. Assim, a prática do rodízio de instituições que a colhiam a Revista, se por um lado garantia a a utonomia em relação às instituições acadêmicas que a abrigavam, por outro lado reforçava a necessidade de buscar a sobrevivência recorrendo a órgãos financiadores, oriundos do campo acadêmico.

Essa sobrevivência fic ou seriamente ameaçada em 1999, e foi nessa ocasião que ocorreu mais um rodízio institucional: a edição da Revista foi então deslocada para Floria nópolis. Desde 1998, os editoria is da Revista Estudos Feministas, a ssina dos por Leila Linha res Barsted, esta va m a lertando para as dific ulda des financ eiras da Revista. Os recursos que tinham obtido de diversos órgãos financiadores não esta vam cobrindo a conta da folha de pagamentos de funcionárias que a Revista tinha assumido. Além disso, o número de assinaturas não era suficiente para garantir autonomia. Assim, a ida da Revista para Florianópolis representou, ta mbém, o reconhecimento de que a vinculação institucional e o suporte que essa poderia representar eram uma possibilidade de sobrevivência.

Em Santa Catarina, foi Miriam Pillar Grossi ${ }^{13}$ - já conhecida por suas pesquisas no campo do gênero e do feminismo - quem recebeu a proposta para dar continuidade a o projeto da Revista. Naquele momento eu - Joana Maria Pedro - era diretora do Centro de Filosofia e Ciências Humanas da Universidade Federal de Santa Catarina e juntamente

\footnotetext{
${ }^{8}$ Nancy S. STERBBACH et al., 1994, p. 287.

9 LAVINAS, 1992, p. 4.

${ }^{10}$ Albertina de Oliveira COSTA, 2004, p. 209.

${ }^{11}$ LAVINAS, 1992, p. 3.

12 LAVINAS, 1992, p. 3.

${ }^{13}$ GROSSI, 2004, p. 215
} 
com uma equipe de pessoas desse centro e do Centro de Comunicação e Expressão estávamos fazendo, a cada dois anos, desde 1994, um encontro intemacional e interdisciplinar chama do "Fazendo Gênero", no qual reuníamos pesquisadoras e pesquisa dores envolvid os com as questões do feminismo e do gênero. Foi, certamente, o envolvimento nessas atividades que tomou as pesquisadoras da UFSC qualificadas para receber esse tipo de proposta.

A transferência para Florianópolis não foi uma decisão apressada. Miriam Pillar Grossi e Cláudia de Lima Costa - as primeiras editoras ${ }^{14}$ - e toda a equipe realizaram inúmera s reuniões com as editoras do Rio e com as representantes da universidade, em Floria nópolis. Em relação a o que oc orria no Rio de J a neiro, podemos a firma r que a Revista deixou de tera "autonomia" desejada, pois se tomou "diretamente institucional", o que nã o esta va no projeto inicial de 1992. A Revista to mou-se, a ssim, uma a tivid a de a c a dêmic a da UFSC, envolvendo, entã o, do is centros de ensino, o CFH e o CCE; por outro la do, ga nhou em infra-estrutura institucional. Desta ma neira, foi publica do o volume 7 , que junta va os números 1 e 2 de 1999.

Uma outra mudança foi a da periodicidade. A partir de 2004, passamos a publicar três números por ano, busc ando a tender às exigências de um dos nossos indexa dores: a Sc iELO. Esse indexador passou a exigir que as revistas do campo das Ciências Humanas public a ssem, inicia Imente, trêse, depois, qua tro números pora no. Após convoc a ras demais revista se entra rem conta to com os representantes da Sc iELO, mostra ndo a dific ulda de que essa exigência representaria, nossa editora à época, Luzinete Simões Minella, juntamente com outros/as ed itores/as das dema is revista s conseguiram que a Sc iELO volta sse a trá s em sua exigência. Mesmo assim, a Revista Estudos Feministas estruturou-se para public ar três números a nuais, não somente para a tend eràs exigências mas ta mbém porque o número de artigos, dossiês e seções temáticas de qualidade estava exigindo a sua ampliação.

Seja no Rio de Ja neiro, seja em Santa Ca tarina, ja ma is a Revista Estudos Feministas conseguiu sobreviver com os recursos provenientes das assina turas, mesmo que inúmeras campanhas e promoções tenham sido feitas. Em Santa Catarina, conseguimos ampliar signific a tiva mente o número delas - recebemos do Rio de J a neiro o registro de a penas três assinaturas que se encontravam em dia. Possuímos, a tualmente, 150 assina turas; mesmo assim, essas não cobrem os custos. Recursos públicos e de outros órgãos financiadores continuam sendo impresc indíveis. Convém salientar que todo trabalho de editoria é voluntário. O que pagamos, na forma de prestação de serviços, é muito pouco comparado com o montante de trabalho gra tuito que realmente produza Revista.

De qualquer maneira " temos que reconhecer ", é a institucionalização da Revista na Universida de Federal de Santa Catarina que tem permitido uma estrutura mínima. Essa junta mente com os a poios financ eiros rec ebid ose as assinatura s pemitem a sob revivência a té o momento. Na UFSC, a REF tem conta do, desde 1999, com alguma infra-estrutura, que, se não é a mais a mpla, tem um mínimo de condições que lhe ga rantem a existência. Uma sala, no terceiro piso do CFH, com ar-condic iona do e telefone - sendo garantidos a luze o telefone pela instituição.

Além disso, o CFH disponibilizou uma secretária, a Carmem Ramos, que tem a companhado a Revista desde que chegou à UFSC. A presença dela é muito importante, na medida em que garante a memória viva do que tem acontecido. As coordenadoras já se reveza ra $m$ vá rias vezes, a s bolsistas ta mbém; entreta nto, a secretá ria Ca rmem, felizmente, permaneceu.

14 Miriam Grossi e Cláudia de Lima Costa foram editoras da Revista entre 1999 e 2001. 
Nesse período de permanência na UFSC, a REF já ocupou um lugar bem menor no espaço físico do CFH. Sua sede era no térreo, uma sala minúscula, que costumávamos chamarde "gaveta". Hoje, embora nã o estejamos, a inda, com o espaço que a Imejamos, já a mplia mos signific a tiva mente o lugar, ga rantind o inc lusive espaço pa ra o a Imoxa rifa do.

Outra questão que tem feito parte da infra-estrutura é a garantia, depois de 2005, da postagem da Revista, um custo signific a tivo que inicialmente fic a va a cargo do CFH e que no momento tem sido dividido ta mbém com o CCE.

Nesse período, temos conseguido junto a alguns órgãos financiadores algumas ajudas diretas e indiretas. Estou chamando de a judas diretas a quelas que são destina das diretamente à public ação da Revista, e indiretasaquelas que foram destinadas a algum evento que previu a publicação de alguma parte da Revista no seu orçamento.

\section{Foram a judas ind iretas:}

\begin{tabular}{lll} 
Ano & Va lor & O rige m \\
\hline 2002 & $\mathrm{R} \$ 280.842,32$ & $\begin{array}{l}\text { Fundação Ford - destina do a o Portal Feminista e à } \\
\text { constituição da Rede de Public ações Feminista s }\end{array}$ \\
2003 & $\mathrm{R} \$ 24.595,00$ & $\begin{array}{l}\text { Sec reta ria Espec ial de Polític as pa ra as Mulheres - } \\
\text { destinad o a o Enc ontro de Public ações Feminista s }\end{array}$ \\
2005 & $\mathrm{R} \$ 23.080,00$ & $\begin{array}{l}\text { Institute of Interna tional Educa tion (IIE) - conseguido } \\
\text { atra vés da Fundação Ford pa ra a c irc ulação da Revista } \\
\text { em eventos naciona is }\end{array}$ \\
& $\mathrm{R} \$ 17.000,00$ & FAPESC - para os 15 a nos da REF
\end{tabular}

Foram a judas diretas:

\begin{tabular}{lll} 
Ano & Valor & Origem \\
\hline 1999 & $\mathrm{R} \$ 12.050,00$ & CNPq \\
2000 & $\mathrm{R} \$ 15.000,00$ & $\mathrm{CNPq}$ \\
2001 & $\mathrm{R} \$ 24.000,00$ & $\mathrm{CNPq}$ \\
2002 & $\mathrm{R} \$ 17.000,00$ & $\mathrm{CNPq}$ \\
2003 & $\mathrm{R} \$ 21.600,00$ & $\mathrm{CNPq}$ \\
2004 & $\mathrm{R} \$ 37.000 .00$ & $\mathrm{CNPq}$ \\
2005 & $\mathrm{R} \$ 23.000,00$ & $\mathrm{CNPq}$ \\
2005 & $\mathrm{R} \$ 30.000,00$ & SEPM \\
2006 & $\mathrm{R} \$ 15.000,00$ & CNPq \\
2006 & $\mathrm{R} \$ 15.000,00$ & CAPES \\
2006 & $\mathrm{R} \$ 10.000,00$ & CEPESC \\
2007 & $\mathrm{R} \$ 20.000,00$ & CAPES/CNPq \\
\hline
\end{tabular}




\section{Esses recursos diretos formam por a no o seguinte montante:}

\begin{tabular}{|c|c|c|c|c|c|}
\hline ANO & $\mathrm{CNPq}$ & SEPM & CAPES & CEPESC & TO TAL \\
\hline 1999 & $12.050,00$ & & & & $12.050,00$ \\
\hline 2000 & $15.000,00$ & & & & $15.000,00$ \\
\hline 2001 & $24.000,00$ & & & & $24.000,00$ \\
\hline 2002 & $17.000,00$ & & & & $17.000,00$ \\
\hline 2003 & $21.600,00$ & & & & $21.600,00$ \\
\hline 2004 & $37.000,00$ & & & & $37.000,00$ \\
\hline 2005 & $23.000,00$ & $30.000,00$ & & & $53.000,00$ \\
\hline 2006 & $15.000,00$ & & $15.000,00$ & $10.000,00$ & $40.000,00$ \\
\hline \multirow[t]{2}{*}{2007} & $10.000,00$ & & $10.000,00$ & & $20.000,00$ \\
\hline & & & & Total & $239.650,00$ \\
\hline
\end{tabular}

Esses rec urso s são ga stos com os seguintes itens: a) ed ito ra ção; b) fo to lito e capa; c) la ser film; d) exec ução da capa; e) revisã o téc nic a; f) grá fica; g) tra nscrição de entrevista s; h) tra duções; i) tonner de tinta; j) bolsista s; I) ma nutenção da Revista Estudos Feministas no site do Portal Feminista e digitalização de revistas como Pagu, Gênero e Espaço Feminino para serem disponibilizadas nesse mesmo site; e $\mathrm{m}$ ) dia gra mação.

De to dosessescustos, o ma ioré o da gráfica, em torno de $\mathrm{R} \$ 8.000,00$, seguido pelo da editora ção, da dia gra ma ção e da coloca ção dos da dos das revista s no Portal Feminista, bem como da manutenção desse portal. Desta maneira, o custo médio de uma revista, impressa e em formato on-line, soma $R \$ 18.000,00$, dando um total de $R \$ 54.000,00$ por a no. Nesse custo, não esta mos levando em conta to do o tra ba lho voluntá rio das ed itora se a contra partida da Universidade Federal de Santa Catarina, que, como já informei, a rca com grande qua ntid a de de a portes. É bom lembrarque essa contra partida da universida de, assim como os recursos oriundos de órgã os financiadores como o CNPq e a Capes, tem relação direta com o fato de a Revista Estudos Feministas ser reconhecida como uma revista com qualidade acadêmica.

Apenas uma pequena parcela das despesas tem sido coberta pela venda da Revista e pelas assinaturas, que, no momento, somam apenas 150 . No quadro abaixo, é possível a companha ro montante de assinaturas que a cumulamos em cada a no.

\section{Assina turas}

$1996-155$

$1997-125$

$1998-81$

$1999-85$

$2000-284$

$2001-322$

$2002-416$

$2003-368$

$2004-277$

$2005-286$

$2006-320$

2007 - 150 
Convém desta carque, em 2002 e em 2005, tivemosa portes importa ntes de recursos que nos a judaram a a mpliar as assinaturas. A Fundação Ford e o Institute of International Education (IIE), respectivamente, proporciona ram recursos que permitiram que as editoras estivessem presentes em diversos eventos acadêmicos e de militância feminista. Nesses eventos, foi possível conseguir vários assinantes da Revista. No momento, continuamos empenhadasnessa ta refa, porém sem ajuda. A presença da Revista nos eventos depende das possibilidades das editoras que viajam para encontros, seminários, colóquios, com recursos próprios ou instituciona is. Neste momento, é o evento Fazendo Gênero que proporciona a melhorpossibilida de de captarnovas assinantese de renovarasjá existentes. Assim, é a cada 2 anos que essas se ampliam.

Gostaria de destacar, mais uma vez, o trabalho voluntário que é desenvolvido na Revista Estudos Feministas. Pa ra se teruma idéia, a coordenação geral da Revista chega a dedicar 15 horas semana is para esse trabalho. É bom lembrarque, para a administração universitária federal, essas horas de trabalho não dispensam ninguém da exigência do número mínimo de aulas, de desenvolver projetos de pesquisa, de orientar trabalhos de conclusão de curso, iniciação científica, dissertação de mestrado, teses de doutorado. Enfim, embora possa constar como trabalho de extensão, essa ta refa precisa ser feita juntamente com todas as dema is obrigações.

Estou, a ba ixo, rela c ionand o a lguns dos tra ba lhos voluntá rios que são desenvolvid os na ela bora ção da Revista. Destaque-se que esse trabalho não é feito a pena spela seditoras, que são professoras da Universidade Federal de Santa Catarina. Esse trabalho é também desenvolvido por professoras da Universidade do Estado de Santa Catarina (Udesc), Universida de Federal de Sa nta C a ta rina (UFSC), pois muita s compõem as diversa s ed ito rias; pora lg uma soriundas da Universida de Federal do Pa raná (UFPR) e, a inda, porpesquisa doras de diferentes lugares do Brasil e do exterior, que gentilmente a judam emitindo pa receres.

Tentei dividir essas tarefas por etapas da elaboração da Revista, as qua is são descritas na seqüência.

1) Seleção do que vai ser publicado: a) leitura inicial por parte das editoras de artigos, dos textos que chegam, e emissão de pareceres preliminares, decidindo o encaminhamento; b) buscarparecerista s que se disponham a colaborar; c) conferir se as parecerista s respond era $m$, a ceita ra $m$, envia ra $m$ pa receres; $d$ ) insistir quando as pareceristas não respondem às mensagens enviadas; e) ler as resenhas enviadas, selecionar as melhores, devolver as rejeitadas e sugerir mudanças; f) acompanhar a organização de dossiês lendo osartigos, propondo mudançase dialogando com as autoras; g) estimulara rea lização de entrevista s; h) receber, ler e a valiar a s entrevista s; e i) escolher qua is a rtigos irão para o próximo número da Revista.

2) Organização das editorias: a) fazer reuniões de editorias específic as; b) fazer reuniões de todas as editorias; e c) garantir um mínimo de harmonia entre as várias componentes assegurando a rotatividade das ta refas, dos encargos e dos prestígios.

3) Divulgação da Revista: a) levara REF na bagagem quando se vai para algum evento local, nacional ou intemacional; b) montar bancas, vender revistas, promover as assinaturas e fazer doações; c) divulgar as assinaturas; e d) montar, a cada ano, um calendário para divulgar a Revista.

4) Elaboração das diversa s partes da Revista impressa: a) propor às pessoas que enviem resenhas; b) coordenar a elaboração da seção Debates; c) insistir para que as pessoasque se comprometeram com o envio de artigoso façam dentro do prazo solic ita do; d) esc rever e normatiza r as minibiog ra fias; e) esc rever ed itoria is; f) a companhar a revisã o téc nic a dos textos conta c tando a utora sque nã o respondem a o revisor, g) a juda ra encontrar, na intermet, as referência s bibliog ráfic as que o revisore a autora nã o possuem (ou nã o têm 
tempo para procurar); h) coordenar a tradução de artigos; i) buscar imagens para as c a pas; j) conferir os sumários; I) revisa ros textos a pós a dia gra ma çã o e a primeira impressã o; m) discutir, com a gráfica, as refo mula ções, os preços, a entrega, a qua lida de da imp ressã o; e n) levar a Revista a té os correios da UFSC.

5) Elaboração da Revista on-line: a) escolher os artigos que serão publicados na SciELO, em inglês; b) participar de reuniões na SciELO; c) a companhar a tradução dos a rtigos escolhid os; e d) colocarna rede a lista dos a rtig os escolhid os e esperar pa cientemente que alguém das outras ed itorias se manifeste.

6) Ma nutenção da Revista : a) pa ga ros serviç os presta dose os fomecedores; b) fazer projetos pedindo recursos; c) escrever solicitações de reconsideração quando enviam poucos recursos; d) fazer rela tórios no prazo; e e) insistir para que o CFH e o C CE continuem cobrindo as despesas com a remessa da Revista.

7) Manutenção do prestígio da Revista: a) enviar cartas pedindo reconsidera ção qua nd o a comissã o do Qua lis Ca pesnã o a va lia bem a Revista; b) busc arnovosind exa dores e manter osjá existentes; c) receber as crític as à s vezes virulenta s que chegam de autora s que tiveram os seus artigos rejeita dos pelas pa receristas extemas; d) editar os pa receres extemosque chegam, evitando, assim, que as a utora s rec ebam pareceres muito duros; e e) administrar as críticas que chegam logo após a publicação da Revista, apontando os erros que ainda são encontrados.

Quand o pensa mosem militância, muita s vezes nos reporta mosa tra ba lhos voluntá rios de ajuda, a poio às pessoas ou objetivos a serem alcançados por um grupo, uma classe, um gênero, uma geração. Fazera Revista Estud os Feministas requer, como se pode ver, uma grande qua ntida de de traba lho voluntário; é possível, então, dizer que este é um traba lho de militância. Um contra-argumento poderia ser o de que as pessoas envolvidas com a editoria de revistas ga nha m prestíg io a c a dêmico e reg istros qua lific a dos no C urríc ulo La ttes e, portanto, haveria uma contra partida em tudo isto. Entretanto, fazeruma revista que é de estudos feministas significa, também, viver no cotidiano acadêmico o desprestígio designado para as pessoas que são consideradas milita ntes em vista do próprio objeto da Revista.

Éóbvio que não é somente a Revista Estudos Feministas que exige toda essa carga de traba lho gra tuito. Ed itores de diferentes revista sa ca dêmic a s vivem esse mesmo dra ma. A ma ioria dispõe de pouquíssimo - ou nenhum - apoio em recursos huma nos, isto qua ndo não fica somente com a pessoa da editoria o encargo de realizar todas as etapas do trabalho, o que leva, muitas vezes, a ter problemas com a periodicidade da revista. Entretanto, em contrapartida, a cademic a mente a pessoa tem o seu traba lho rec onhecido pelos pares.

Essa constatação me leva a refletir as vantagens e as desvantagens de participar da editoria da Revista Estudos Feministas. A grande desvantagem é a desqualificação constante pelospares de seresta uma revista considerada militante; entretanto, é o próprio caráter militante da Revista que permite a existência de expressiva partic ipação da equipe em todo esse trabalho voluntá rio. Certa mente a mesma militância que é resp onsá vel pelo desp restígio acadêmico de quem nela trabalha é, também, a sua impulsionadora.

Uma outra característic a que tem ajuda do a conseguir a poio é a a doção de rodízio nas diferentes editorias da Revista. Não há uma "editora" da Revista que se perpetue neste lug a ra tra vés dosa nos: há coordena ções ed itoria is, há editora s. Nã o há uma divisão cla ra - como costuma a contecerem vá ria sed itorias - entre as pessoas que a penas desenvolvem ta refas precisas, enqua nto outras decidem as polític as e desfruta m do pouco prestígio que a editoria proporciona. Envolver-se em qualquer das ta refas da Revista, pertencera a lguma editoria, significa efetivamente muito trabalho, mas também significa a possibilidade de 
participar da tomada de decisões e de vir a ser reconhecida como parte dessa revista, enfim, reconhecer-se nela.

Reconhecidamente, nã o é fá cil administra r os conflitos que uma editoria com esse c a rá ter horizonta liza do proporciona. Entretanto, pelo menos por enqua nto, as disputas, os embates têm sido menores do que o empenho, o a poio, a solida rieda de, o engaja mento. Ao final, no equilíbrio entre academia e militância, a Revista Estudos Feministas tem conseguido seguir, completando 15 a nos de existência.

\section{Referências bibliográficas}

COSTA, Albertina de Oliveira. "Revista Estudos Feministas: primeira fase, locação Rio de J a neiro". Revista Estudos Feministas, Floria nópolis: CFH/C CE/UFSC, v. 12, número especial, p. 205-210, 2004.

COSTA, Ana Alice Alcântara; SARDENBERG, C ecília Maria Ba c ellar. "Teoria e práxis feminista na academia. Os núcleos de estudos sobre a mulher nas universidades brasileiras". Revista Estudos Feministas, Floria nópolis: CFH/C CE/UFSC, número especial, p. 387-400, 2. sem. 1994.

GROSSI, Miriam Pillar. "A Revista Estudos Feministas faz 10 anos. Uma breve história do feminismo no Brasil". Revista Estudos Feministas, Floria nópolis: CFH/CCE/UFSC, v. 12, p. 211-221, 2004.

LAVINAS, Lena. "Editorial". Revista Estudos Feministas, Rio de J a neiro: C IEC/EC O/UFRJ , n. 0, p. 3-4, 1992.

MIGUEL, Sônia Malheiros. Um olhar para dentro: o movimento feminista no Rio de J aneiro. 1988. Dissertação (Mestrado em Ciências Sociais) " Universidade Federal de Santa Catarina, Florianópolis.

PEDRO, Joana Maria. "Feminismo e gênero na universidade: trajetórias e tensões da militância." História Unisinos, São Leopoldo/RS, v. 9, n. 3, p. 170-176, 2005.

. "Revista Estudos Feministas: estra tégias de institucionalização e produção do conhecimento". In: BRASIL. Presidência da República. Secretaria Especial de Políticas para as Mulheres. Pensando gênero e ciência. 2006. p. 53-63.

SAFFIOT, Heleieth la ra Bongiovani. A mulher na sociedade de classes: mito e realidade. Petrópolis/RJ : Vozes, 1979.

STERBBACH, Nancy S. et al. "Feministas na América Latina: de Bogotá a San Bemardo". Revista Estudos Feministas, Rio de J a neiro: CIEC/ECO/UFRJ , v. 2, n. 2, p. 255-295, 1994.

[Rec ebido em ja neiro de 2008 e aceito para publicação em março de 2008]

Feminist Activism and Academy: Continuation and Voluntary Work

Abstract: The continuation of an a cademic journal in Brazil depends on financial and institutional support in addition to the -so metimes overwhelming- editors' hard work. Revista Estudos Feministas, atonce an academic and an activist journal, has had the participa tion of many unpaid collaborators. This artic le disc usses the journal's continuation possibilities, the diffic ulties it faces when it is id entified by many as an activist journal, although it gets voluntary support for the sa me reason. Key Words: Activism; Academy; Voluntary Work. 